\title{
The aetiology and pathogenesis of hyperthyroidism
}

\author{
Basil S. Hetzel* \\ M.D., M.R.C.P., F.R.A.C.P. \\ Department of Medicine, University of Adelaide, \\ The Queen Elizabeth Hospital, Woodville, South Australia
}

\section{Summary}

Studies of thyroid stimulating activity of serum from thyrotoxic patients has revealed an abnormal prolonged response in the mouse present in $40-60 \%$ of patients depending on the criteria used. This agent designated long acting thyroid stimulator (LATS) is a 7S globulin. Transplacental passage of LATS accounts for neonatal thyrotoxicosis-a self-limited disease. LATS is also more readily detected in patients with large goitre, exophthalmos, pretibial myxoedema and recurrence following therapy. Thyroid ablation is usually followed by a fall in the level of LATS. A fall may also be produced by steroid therapy or immunosuppressive agents. LATS probably arises from lymphoid tissue which accounts for the non-suppressibility of the hypersecreting thyroid. Its discovery provides strong evidence that hyperthyroidism is often, though not always, a disorder of immunological tolerance.

\section{Introduction}

Hyperthyroidism is a syndrome with many causes. It is characterized by the presence of excessive quantities of thyroid hormones in the circulation. The term 'thyrotoxicosis' is often used, especially in British medicine, to denote this state which has very characteristic clinical features, including a hyperdynamic circulation, loss of weight and muscle weakness with increased excitability of the autonomic nervous system.

There are many recognized causes of hyperthyroidism such as the ingestion of excess quantities of thyroid hormones ('thyrotoxicosis factitia') or the production of excess thyrotropin from pituitary tumours ; transient release of excess thyroid hormone from administration of thyrotropin or as a result of injury due to inflammation (subacute thyroiditis) or radiation; hypersecreting nodules in the thyroid gland

* Michell Professor of Medicine, University of Adelaide, Adelaide, South Australia. ('toxic adenoma' which may be single or multiple), ectopic thyroid tissue or carcinomata. All these conditions are uncommon and even rare. Thyrotoxicosis usually occurs without evidence of any of them.

Usually thyrotoxicosis is accompanied by a general hyperplasia of the gland which in younger patients is clinically evident as a smooth diffuse enlargement and in older patients as a multinodular enlargement. In younger patients this condition is often accompanied by bilateral eye protrusion or exophthalmos but this is uncommon in older patients. In the U.S.A. the term 'Graves' Disease' is often used to denote this condition of exophthalmos and hyperthyroidism. 'Parry's Disease' would recognize Parry's priority over Graves but his first description is generally recognized. The term 'toxic goitre' is also in general use.

\section{Aetiological factors}

Certain clinical associations are characteristic of this condition-it is commoner in women, it has a familial incidence and it often follows acute or chronic emotional disturbance due to stressful life situations. Its incidence rises in areas where endemic goitre is found.

Warthin (1928) emphasized the importance of the 'Graves' constitution'-characterized by general lymphoid hyperplasia-being inherited as a predisposing factor. Recent evidence to be cited below is throwing new light on Warthin's postulate.

Each of the three major clinical associations already cited will now be considered in more detail because of their aetiological importance.

\section{Familial incidence}

Bartels (1941) found a familial predisposition in $60 \%$ of his cases of toxic diffuse goitre. Martin \& Fisher (1945) found evidence of a recessive factor. The author has seen one family in whom two brothers at the ages of 24 and 35 each had a subtotal thyroidectomy for thyrotoxicosis. Sub- 
sequently their daughters at the ages of 18 and 11 also required thyroidectomy for severe thyrotoxicosis with exophthalmos. Harvald \& Hauge (1956) in a retrospective study found thyrotoxicosis in twelve co-twins of forty-one thyrotoxic probands of monozygotic pairs compared with only two co-twins affected of fifty-nine dizygotic pairs of the same sex. Ingbar et al. (1956) have reported more rapid turnover of thyroxine and a higher uptake of radio-iodine in relatives of patients with thyrotoxicosis who are euthyroid.

More recently, thyrotoxicosis has been reported in four sets of identical twins (Hassan et al., 1966) who also showed concordance for significant titres of thyroid antibodies-complement fixing antibody to microsomal antigen and also gastric parietal cell antigen. There is a significant familial association between thyrotoxicosis and Hashimoto's disease (Means, de Groot \& Stanbury, 1963) to which further reference will be made below.

\section{Psychosocial stress}

The association of emotional disturbance in the form of acute shock was noted by Parry (1825) in his second case who presented herself on 28 April 1803 with symptoms following a fall from a wheel-chair 2 weeks before. Acute emotional trauma is still occasionally noted as in two recent personal cases seen following minor vehicular accidents. Such acute trauma is much less common than chronic disturbance-due to chronic family or marital stress, overloading with personal responsibilities, chronic financial difficulties or upheavals due to migration. Varying figures have been given as to the incidence of such stressful life-situations in a substantial series of patients depending to some extent on the viewpoint and geographical situation of various investigators. Earlier psychoanalytically oriented psychiatrists have given figures up to $94 \%$ (Conrad, 1934). Hetzel (1960) noted significant coincident stressful life-situations in over $80 \%$ of a series of forty patients studied in New York City but an incidence of only $65 \%$ in a series studied in Adelaide, Australia. Comparison of the incidence of stressful life-situations in other groups of patients suffering from non-toxic goitre and myxoedema in Adelaide revealed a similar incidence of $65 \%$ (Brown \& Hetzel, 1963).

More penetrating studies reveal that the thyrotoxic patient shows evidence of marked depression which disappears following satisfactory treatment (Brown \& Hetzel, 1963). This will inevitably influence their attitudes to current lifesituations so that their histories will be influ- enced and cannot therefore be accepted as 'objective' evidence of their environmental situation. This effect of the disease makes it more difficult to draw conclusions from earlier studies on untreated patients.

Studies of thyroid function in normal subjects subjected to stressful interviews (Hetzel et al., 1956), acutely disturbed patients admitted to psychiatric hospitals (Board, Wadeson \& Persky, 1957) and in medical students undergoing examinations (Tingley, Morris \& Hill, 1958) have revealed modest elevations of circulating thyroid hormones as indicated by plasma PBI levels. In general the plasma PBI is not so labile as the plasma corticosteroid level but does exhibit a similar pattern of changes (Hetzel, 1960). Initial studies in rats and rabbits showed thyroid inhibition during restraint or faradic shock (Brown Grant, Harris \& Reichlin, 1954). However, thyroid activation has been demonstrated following hypothalamic stimulation, especially if the rabbit is adrenalectomized first (Harris \& Woods, 1958). More recently, stimulation of the limbic area of the cerebral cortex in dogs has resulted in increased TSH secretion and thyroid activation (Shizume et al., 1962). Falconer \& Hetzel (1964) were able to demonstrate rises in plasma PBI and PB $^{131} I$ in thyroid vein blood in the sheep when under restraint or exposed to a barking spaniel dog. These changes could be reproduced by TSH administration but not by adrenaline.

All these observations indicate that there is a neuroendocrine mechanism acting through the hypothalamus producing activation of the pituitary via the secretion of thyrotropin-releasing factor (TRF) through the pituitary portal system. However this neuroendocrine mechanism now seems less likely as a common mechanism in thyrotoxicosis for reasons that will be given below.

\section{Endemic and epidemic thyrotoxicosis}

There is much evidence indicating that endemic goitre predisposes to thyrotoxicosis (Clements, 1960) - the geographical distribution of thyrotoxicosis coincides with areas of high incidence of endemic goitre in North America (McClendon, 1939).

In a study in the various Australian states Clements (1954) showed that death rates for thyrotoxicosis were highest in those states with the highest incidence of endemic goitre. However, there is a lack of evidence of thyrotoxicosis in more remote Highland areas such as the Himalayas, the Andes and in New Guinea, where there is a high incidence of endemic goitre. It may have been overlooked in these 
areas but this seems unlikely although Perinetti (1952) has reported a relatively high prevalence of toxic nodular goitre in Mendoza, Argentina.

Plummer (1931) made the original observation that there was an 'epidemic' of thyrotoxicosis in the Great Lakes Region after 1923 reaching a peak in 1926 and 1927 and then receding to the 1923 level by 1931. He observed the number of cases coming to the Mayo Clinicwhich rose three to four times over this period. The increase was particularly evident in patients with long-standing goitre. There is also evidence of an increase in thyroid operations for thyrotoxicosis due to toxic nodular goitre in Detroit over the same period (McClure, 1934); there was a peak in 1927 with 1452 operations and a gradual fall to 1933, when there were only 591 operations-a much greater fall than occurred in all surgical operations.

McClure raised the possibility that the increase was related to the introduction of iodized salt as a prophylaxis against endemic goitre. Plummer dismissed this possibility but there has been continued controversy ever since. The occurrence of this Mid-Western 'epidemic' was accepted by Marine (1954). However, no such 'epidemic' has been reported in other parts of the world following iodization programmes.

A sharp increase in incidence of thyrotoxicosis was reported in the civilian population during the Second World War by Meulengracht (1945) in Denmark and by Grelland (1946) in Norway. Meulengracht $(1945,1949)$ was unable to decide on the cause of the 'epidemic'-and suggested 'a specific infective agent of unknown nature' might be responsible.

Greenwald (1962) has claimed that there has been an increase in death-rate from thyrotoxicosis in many countries after 1923, including Canada, U.S.A. and U.K. More recently, Greenwald (1965) has made a similar claim for Australia following analysis of the death-rate per million females from 1907 to 1945 and also considered these findings favoured an infectious agent. This seems unlikely as Clements (1954) has pointed out that there is a progressive age increase in these cases and makes the alternative suggestion that these cases represent a residue of people who have suffered from endemic goitre in earlier life.

\section{The pathogenesis of hyperthyroidism}

The major question to be solved in the pathogenesis of hyperthyroidism is the mechanism responsible for oversecretion by the thyroid gland.
Various views have been held in the past depending on successive advances in physiology and biochemistry. Charcot (1856) regarded the condition as a neurosis until Moebius pointed out the associated goitre. The demonstration that iodine was a component of the thyroid gland by Baumann in 1895 led eventually to the postulate that the disorder was essentially one of iodine metabolism. The demonstration by Cannon of the physiological effects of adrenaline led to the postulate of a mechanism via the sympathetic nervous system. The recognition of pituitary thyroid control and preparation of potent pituitary extracts by Evans, Smith and Smith and others in the early 1920 s led to the claim of experimental production of exophthalmos and hyperthyroidism in the rat by pituitary extracts (Marine \& Rosen, 1934). These findings led to the postulate of hyperpituitarism as the mechanism of the disorder (Marine, 1935).

A characteristic feature, recognized after 1950, is that the hypersecreting gland is not suppressed by the administration of thyroxine or triiodothyronine, even in very large doses, in contrast to the normal gland (Werner, 1955). While this property is not always associated with elevated levels of circulating thyroid hormones it usually is. Where it is not the gland is hypersecreting from a small pool of hormone due to previous surgery, or thyroiditis due to various causes (Liddle, Heyssel \& McKenzie, 1965). This property suggested to Werner (1955) that the thyroid gland itself was at fault and not the pituitary trophic hormone secretion.

The high effectiveness of therapy for thyrotoxicosis based on partial ablation of the thyroid gland contrasts strikingly with the tendency to recurrence of hyperadrenalism following partial ablation of hyperplastic adrenal glands; this observation was in keeping with the suggestion that the disorder resided within the thyroid itself. Plummer had originally suggested that exophalmic goitre patients were suffering from 'dysthyroidism' or an abnormal thyroid secretion (Means, 1937). This and other similar postulates raises the question of the nature of thyroid secretion in thyrotoxicosis.

\section{Pattern of thyroid secretion}

Studies of the nature of thyroid secretion in thyrotoxicosis have been carried out with the help of recently developed methods for chromatographic separation of the iodoamino acids following prior administration of radio-iodine to the patient. These methods resulted in the discovery of triiodothyronine $\left(\mathrm{T}_{3}\right)$ by Gross \& PittRivers (1952) in four thyrotoxic patients and 
two patients with thyroid carcinoma following therapeutic doses of radio-iodine.

The presence of excessive quantities of $T_{3}$ and thyroxine $\left(\mathrm{T}_{4}\right)$ in the plasma of thyrotoxic patients compared to normal subjects was subsequently confirmed by the use of chemical methods of detection (Maclagan, Bowden \& Wilkinson, 1957 ; Wellby \& Hetzel, 1962). However, an excess of iodotyrosines-both monoiodotyrosine (MIT) and diiodotyrosine (DIT)has also been demonstrated in $50-70 \%$ of thyrotoxic patients (Farren et al., 1959; Bird \& Farran, 1960 ; Wellby \& Hetzel, 1962 ; Wellby, Hetzel \& Good, 1963a) using both radioactive and chemical methods so that artifacts are largely excluded. This finding raised again the possibility of 'dysthyroidism' as originally suggested by Plummer.

Subsequent studies indicated that this characteristic circulating secretion pattern of excess $T_{3}$, $T_{4}$ and iodotyrosines could be reproduced in the normal subject by administration of thyrotropic hormone (Wellby \& Hetzel, 1962 ; Wellby, Hetzel \& Isaachsen, 1963b). The presence of iodotyrosines is not therefore an indication of dysthyroidism but simply an effect of hypersecretion by the gland-associated with an overloading of the deiodinase system. A similar pattern can be demonstrated in the deiodinase defect-one of the biosynthetic disorders producing goitrous cretinism or juvenile hypothyroidism (Stanbury et al., 1955; Niall et al., 1968). The loss of iodine through loss of iodotyrosines from the gland may well favour the production of the more rapidly acting $T_{3}$ rather than $T_{4}$-which would be more appropriate in situations requiring rapid mobilization of body functions (Welby \& Hetzel, 1962).

We conclude, therefore, that there is no evidence for a qualitatively abnormal secretion in thyrotoxicosis. Other phenomena such as excessive activity of the sympathetic nervous system are the result of hyperthyroidism and not its cause-augmentation of sympathetic responses to adrenaline has long been known to occur following administration of thyroid hormones (Hetzel et al., 1958).

\section{The long acting thyroid stimulator (LATS)}

Further elucidation of the mechanism of hyperthyroidism depended on studies of the nature of the thyroid-stimulating activity of the blood of the thyrotoxic patient. Normally undetectable in normal serum, significant activity could be demonstrated in serum from thyrotoxic patients using a number of methods depending on thyroid stimulation in various animal species including the chick and the tadpole (Purves \& Adams, 1960). In general this activity was more evident in sera taken from patients who had exophthalmos as well as hyperthyroidism (Purves \& Adams, 1960).

It was Adams in 1956 who first noticed that the thyroid-stimulating activity of blood plasma taken from thyrotoxic patients differed from that of normal TSH. When administered to the guinea-pig previously given radioiodine the response of the thyroid was more prolonged-with a maximum rise in blood radio-iodine at 16-24 hr following administration of sera from thyrotoxic patients compared with a maximum at 2-3 hr for pituitary extracts or thyroid-stimulating hormone (TSH) (Adams, 1958). These findings were subsequently confirmed by McKenzie in the mouse (McKenzie, 1958)-typical examples are shown in Fig. 1 which shows a comparison

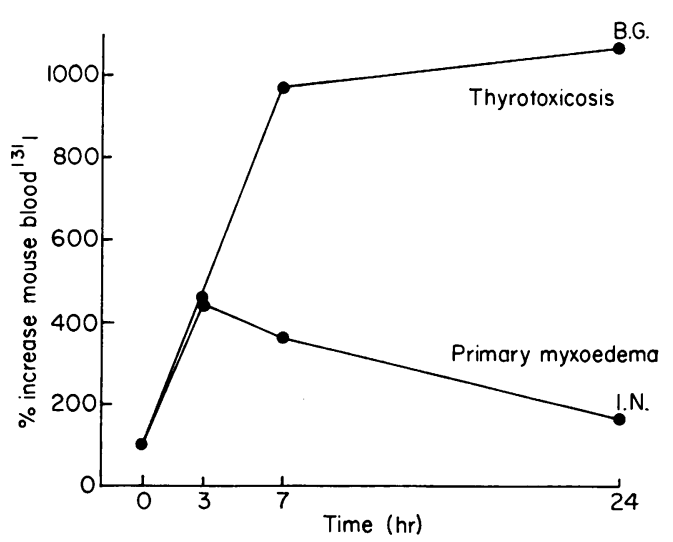

Fig. 1. Comparison of the mouse thyroid stimulating effect of serum from a patient (Mrs B.G.) with untreated thyrotoxicosis, exophthalmos and pretibial myxoedema with the effect of serum from a patient (Mrs I.N.) suffering from primary myxoedema (serum PBI $1.5 \mu \mathrm{g} / 100 \mathrm{ml}$ ). The difference in the effects not apparent at $3 \mathrm{hr}$ is apparent at 7 and $24 \mathrm{hr}$ after injection. The mice are prepared by administration of $5 \mu \mathrm{Ci}$ of radio-iodine 4 days before injection of the sera. The effect of pituitary TSH is similar to that of myxoedema serum. Blood from normal persons produces no response.

of the mouse-thyroid-stimulating effect of serum from a thyrotoxic patient with the activity of serum containing pituitary TSH taken from a patient suffering from primary myxoedema. These different time-courses of the responses were subsequently correlated with the disappearance rates in the circulation of the rat of the thyroid-stimulating principles. Following intravascular injection the activity of thyrotoxic serum had a half-life thirty times that of TSH. A prolonged response can also be obtained by 
repeated administration of TSH in divided doses (Hoffman et al., 1967), suggesting a similar mode of action of the two principles on the thyroid gland. When sera known to contain TSH and the abnormal activity are mixed the effect of the two agents is additive (Adams, 1958; Munro, 1959). The thyroid-stimulating activity of thyrotoxic plasma was also evident in the hypophysectomized mouse indicating that it acts directly on the thyroid. By general agreement the agent causing this thyroid-stimulating activity has been named 'long-acting thyroid-stimulator' (Adams, 1961).

Immunological differences between TSH and LATS have been demonstrated by study of the effects of antisera to bovine and human TSH on each agent (Adams et al., 1962; McKenzie \& Fishman, 1960 ; Werner et al., 1960). Administration of a rabbit antiserum to bovine TSH will grossly diminish or abolish the activity of bovine TSH in the mouse. It will also diminish the mouse-thyroid-stimulating activity of plasma from hypothyroid patients (Fig. 2) but has no



Fig. 2. Reduction of mouse thyroid response to plasma from three hypothyroid patients by mixing with rabbit antiserum (AS) to bovine TSH (NRS indicates normal rabbit serum). (Reproduced from Hoffmann et al., Aust. Ann. Med., 1967.)

effect on the thyroid stimulation of LATS (Fig. 3). On the other hand, mixing a thyrotoxic plasma with an antiserum to $7 \mathrm{~S} \gamma$-globulin prepared in the sheep significantly impairs its mousethyroid-stimulating activity (Fig. 4) but it has no such effect on TSH or the activity of plasma from a hypothyroid patient (Kriss, Pleshakov \& Chien, 1964 ; Dorrington \& Munro, 1965 ; Adams \& Sharard, 1965 ; Hoffmann et al., 1967). Recent determinations of human TSH by immunoassay failed to reveal detectable levels in thyrotoxic sera (Odell, Wilber \& Paul, 1965). Pituitary TSH

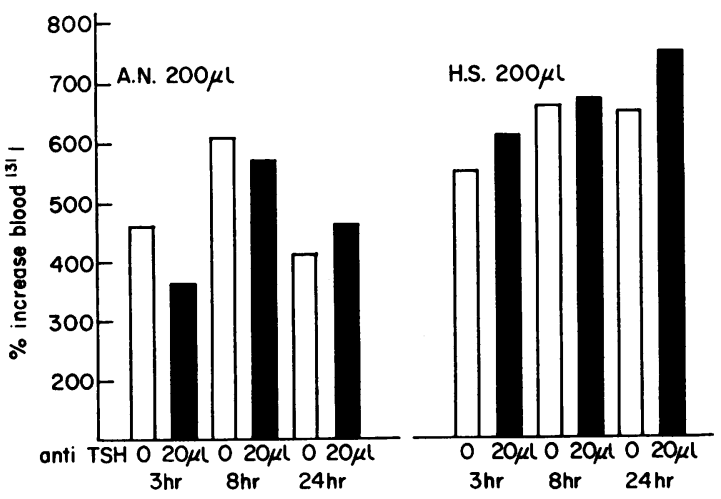

Fig. 3. Absence of effect of rabbit antiserum to bovine TSH on the mouse thyroid response to plasma from two thyrotoxic patients. (Reproduced from Hoffman et al., Aust. Ann. Med., 1967.)

can, however, be demonstrated when hypothyroidism develops following treatment for thyrotoxicosis (Adams \& Kennedy, 1965).

These findings indicate definite differences between the thyroid stimulating activity of sera from thyrotoxic and hypothyroid patients. They raise the possibility that LATS may be a $\gamma$-globulin. Preliminary studies indicated that LATS is rather more sensitive to heat than TSHLATS is inactivated by heating at $70^{\circ} \mathrm{C}$ whereas TSH is only partially inactivated at $70^{\circ} \mathrm{C}$. On the other hand, human antibody to thyroglobulin is also inactivated at $70^{\circ} \mathrm{C}$ (McGiven, Adams \& Purves, 1965).

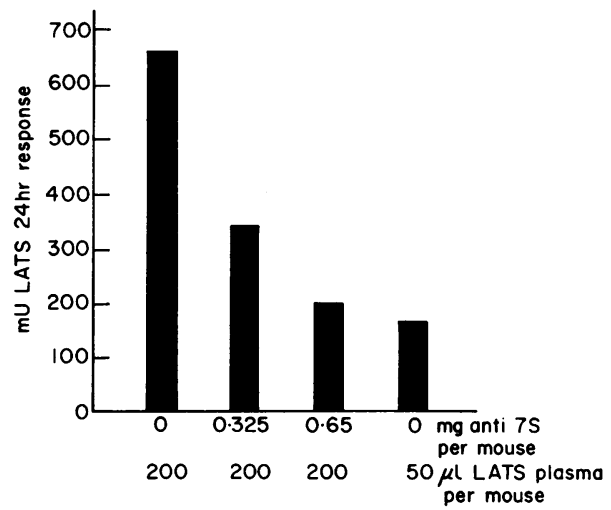

Fig. 4. Reduction of the mouse thyroid response to plasma from a thyrotoxic patient (O.C.) by mixing with sheep anti-7S human $\gamma$-globulin. The response of $200 \mu$ l plasma has been reduced to that of $50 \mu$ l by mixing with $0.65 \mathrm{mg}$ of the sheep antiserum. (Reproduced from Hoffmann et al., Aust. Ann. Med., 1967.) 
Using recently introduced methods of gel filtration the serum proteins can be separated into three main fractions-macroglobulins, 7S $\gamma$-globulins and albumins, as described by Flodin \& Killander (1962). Studies of sera from thyrotoxic patients (with Sephadex G-200) indicate that LATS activity resides mainly in the $7 \mathrm{~S} \gamma$-globulin (IgG) region (Fig. 5) (McKenzie, 1962; Kriss et al., 1964; Hoffmann et al., 1967). Further concentration of the 7S $\gamma$-globulin can be achieved with DEAE Sephadex which also concentrates the thyroid-stimulating activity (Kriss et al., 1964 ; Miyai \& Werner, 1966 ; Hoffmann et al., 1967).

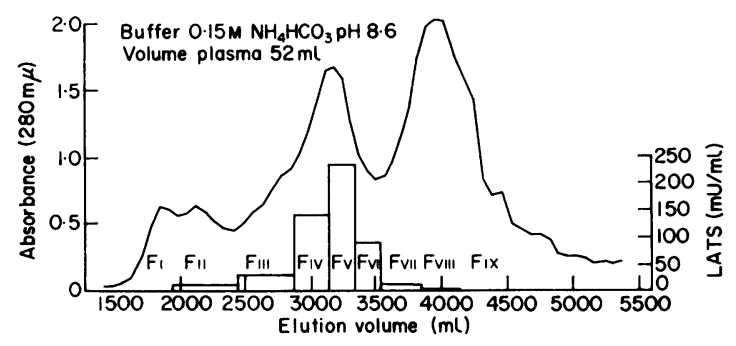

Fig. 5. Results of fractionation on Sephadex G-200 of plasma from a thyrotoxic patient (H.S.) by gel filtration showing localization of long-acting thyroid stimulator (LATS) activity mainly in the $7 \mathrm{~S} \gamma$-globulin region, as indicated by the histograms which represent the results of the mouse bioassay using the method of Mason et al. (1967). (Reproduced from Hoffmann et al., Aust. Ann. Med., 1967.)

Studies of the effect on LATS of procedures known to fragment $\gamma$-globulins (Cohen \& Porter, 1964) have revealed that the biological activity resides in the molecule itself and is not bound to the $\gamma$-globulin (Dorrington, Carneiro \& Munro 1965 ; Kriss et al., 1965). Breakage of the two polypeptide chains by mercaptoethanol followed by gel filtration showed that the activity remains with the heavy (A) chain. Papain digestion (activated by cysteine) gives two slow (S-) fragments and one fast $(\mathrm{F}-)$ fragment-the mousestimulating activity remains with the slow (S-) fragment and now becomes of shorter duration consistent with the smaller molecular weight $(50,000$ compared with 150,000 in the original 7S globulin). Pepsin digestion (pH 4.0), on the other hand, causes a breakdown to a fragment with molecular weight 100,000 -which still has long-acting activity. However, subsequent hydrolysis with cysteine produces a further cleavage to a fragment with a molecular weight 50,000 which has short-acting activity. These findings clearly indicate that LATS activity is in a specific part of the $\gamma$-globulin molecule in the slow fragment, which has been shown to contain the antigenbinding capacity of other antibodies (Cohen \& Porter, 1964). It is not due to TSH being bound to $\gamma$-globulin. Adams (1965) has suggested that it should be renamed 'thyroid-stimulating globulin'.

These findings provide definite evidence of the nature of LATS and therefore have major implications for our future understanding of thyrotoxicosis. As LATS is a $\gamma$-globulin it would be expected to arise from an antigenic stimulus.

Kriss et al. (1964) showed that LATS activity could be inhibited by incubation with humanthyroid slices and dog thyroid slices. Subsequent studies (Beall \& Solomon, 1966a, b) have shown that LATS can be consistently removed from serum by a thyroid microsomal fraction and subsequently eluted from the microsomes under conditions appropriate for dissociation of antigen-antibody complexes. However, mixtures of LATS containing serum and thyroid microsomes did not fix complement. This thyroid microsomal fraction also inhibited the biological activity of LATS more than any other subcellular fraction. Microsomal fractions from six other non-thyroidal tissues did not inhibit LATS. Beall \& Solomon (1966b) suggest these findings sup port the hypothesis that LATS is an antibody reacting with an antigen in the thyroid micro somal fraction.

\section{Neonatal thyrotoxicosis}

Rather striking confirmation of the possibility that LATS is a $7 \mathrm{~S} \gamma$-globulin is provided by the phenomenon of neonatal thyrotoxicosis-a transient form of hyperthyroidism occurring in newborn babies of women with a past history of or at present suffering from thyrotoxicosis. An example of one of these babies is shown in Fig. 6 (Hoffmann, Hetzel \& Manson, 1966). This male baby had an uneventful delivery but in the first 2 weeks was noted to be unduly irritable and was sleeping poorly. He was admitted to hospital and found to be hyperactive with a tachycardia. A week later the infant was observed to have bilateral exophthalmos but not detectable enlargement of the thyroid. The plasma PBI was found to be $12.0 \mu \mathrm{g} / 100 \mathrm{ml}$ at 5 weeks of age. The mother when examined was clinically thyrotoxic with a plasma PBI of 10.9 $\mu \mathrm{g} / 100 \mathrm{ml}$ (Fig. 7). She had developed bilateral exophthalmos since a subtotal thyroidectomy had been carried out 18 months before. The baby received barbiturate therapy only and made a complete recovery within 3 months as is usual with this condition (McKenzie, 1964).

Assays for LATS in the plasma of both 


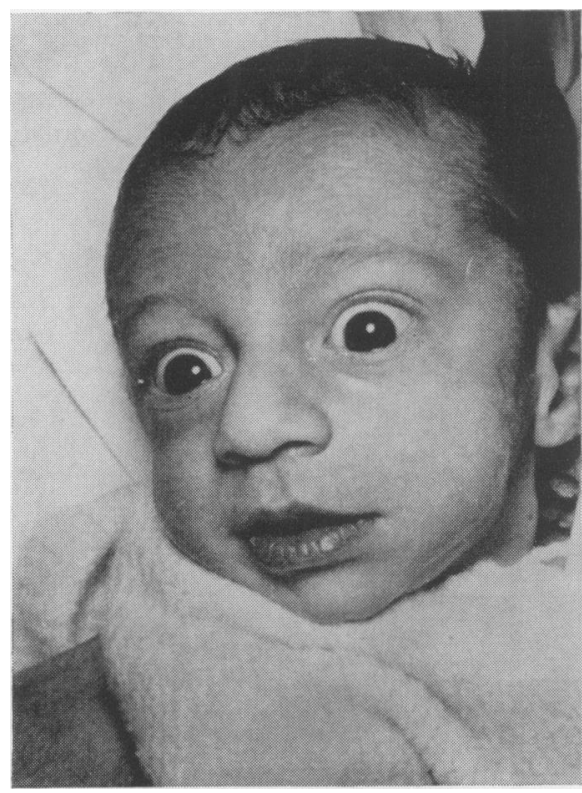

FIG. 6. Baby $S$. at the age of $4 \frac{1}{2}$ weeks showing suggestive appearance of exophthalmos. (Reproduced from Hoffmann et al., Aust. Ann. Med., 1966.)

mother and baby at the age of 5 weeks revealed significant activity. Subsequent assays of the baby's plasma at 11 weeks, 14 weeks and 8 months of age were negative. These results indicate the transient presence of LATS associated with transient hyperthyroidism and are in accord with a biological half-life of 3 weeks for LATS (McKenzie, 1964). The situation is clearly similar to the transient passive immunity of the newborn dependent on the passage of maternal antibodies-7S globulin (IgG) across the placental barrier.

The occurrence of exophthalmos in these thyrotoxic babies is of great interest. Keynes (1952) reported congenital exophthalmos without thyrotoxicosis in a child born to a mother who had developed progressive exophthalmos following subtotal thyroidectomy for thyrotoxicosis 12 months before. These findings strongly suggest a significant role for LATS in the mechanism not only of hyperthyroidism but also of exophthalmos.

\section{Clinical features in relation to LATS}

At this point let us review some of the clinical features of thyrotoxicosis in the adult to see whether they can be related significantly to the level of LATS in the blood of the patient.

The incidence of detectable levels of LATS in the plasma of untreated thyrotoxic patients has been found to be $60-70 \%$ in a number of recent series (Munro, Major \& Wilson, 1960 ; McKenzie, 1961 ; Noguchi, Kurihara \& Sato, 1964 ; Hoffmann \& Hetzel, 1966 ; Carneiro, Dorrington \& Munro, 1966a). In our own series (Hoffmann \& Hetzel, 1966) a significantly higher LATS level was noted in those patients with visible goitre (size 2, Perez, Scrimshaw \& Munez, 1948) as opposed to non-visible although usually palpable goitre. This is consistent with the observation of Noguchi et al. (1964) of a correlation between thyroid cell height and the plasma LATS. Carneiro et al. (1966a) found a correlation between gland mass and the level of plasma PB $^{131}$ I $48 \mathrm{hr}$ after a tracer dose and serum LATS. They found a particularly close correlation between serum LATS and PB $^{131} I$ when divided by the estimated gland mass. This they regarded as a measure of the rate of production of 131I-labelled hormone per unit weight of thyroid tissue. These findings indicate clearly the close relation between serum LATS and the hypersecreting thyroid as already demonstrated in neonatal thyrotoxicosis. It should also be noted that concentration of inactive sera using various methods known to concentrate IgG increased the number of positive samples to $85 \%$ (Carneiro, Dorrington \& Munro, 1966b). This finding suggests LATS may well be the common mechanism in cases of hyperthyroidism.

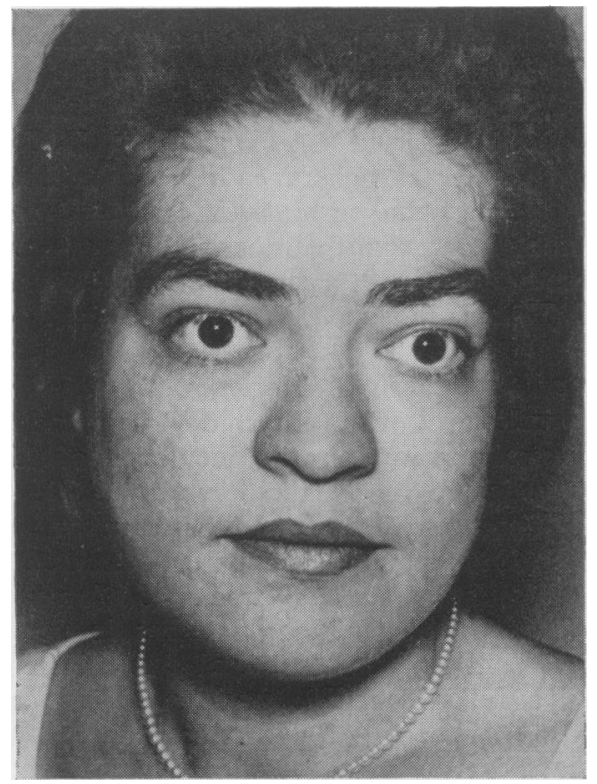

FIG. 7. Mrs S. showing bilateral exophthalmos (exophthalmometer readings $21 \mathrm{~mm}$ each side) 2 years after subtotal thyroidectomy for thyrotoxicosis. (Reproduced from Hoffmann et al., Aust. Ann. Med., 1966.) 
There is, however, no apparent relation between the severity of the illness and the level of plasma LATS (Hoffmann \& Hetzel, 1966 ; Carneiro et al., 1966a). There was no sex difference and there was no difference found between those patients with 'nodular' or 'smooth' goitre (Hoffmann \& Hetzel, 1966 ; Carneiro et al., 1966a).

Some investigators have reported that a significant correlation could be established between exophthalmos and plasma LATS (McKenzie, 1961 ; Pimstone, Hoffenberg \& Black, 1963 ; Hoffmann \& Hetzel, 1966); patients showing only exophthalmos without hyperthyroidism are less likely to show LATS. Satisfactory correlations between parallel assays for LATS and the exophthalmos-producing substance (EPS) have not been demonstrated (Pimstone et al., 1963 ; Dobyns, Rudd \& Liebe, 1965) although in one series LATS correlated better with exophthalmos than with EPS (Pimstone et al., 1963).

An association between high serum LATS and pretibial myxoedema was first pointed out by Kriss et al. (1964) and has since been confirmed (Hoffmann \& Hetzel, 1966; Carneiro et al., 1966a). Disappearance of serum LATS has been associated with spontaneous improvement in pretibial myxoedema (Hoffmann \& Hetzel, 1966). The presence of LATS in pretibial myxoedematous tissue has been claimed (Pimstone et al., 1963) and denied (Pinchera, Pinchera \& Stanbury, 1965).

While there is no association between LATS and the initial severity of thyrotoxicosis there is a correlation between the liability to recurrence and the initial serum LATS (Fig. 8) (Hoffmann \& Hetzel, 1966 ; Pinchera et al., 1965). There is also a greater tendency to exacerbation or the occurrence of exophthalmos following therapy in those patients with a significant level of serum LATS (Hetzel, Mason \& Wang, 1968).

\section{Effect of treatment}

The influence of antithyroid drugs and subtotal thyroidectomy on the incidence of LATS was investigated by Noguchi et al. (1964). Only slight differences were found between untreated patients (68\% positive) and patients treated with antithyroid drugs for $2-3$ weeks (54\% positive) or 4-6 weeks $(50 \%)$. Serial studies in forty-six patients undergoing subtotal thyroidectomy showed a fall from $65 \%$ positive before operation to $17 \%$ positive $2-4$ months later. A transient increase in the incidence of positive responses was noted following radio-iodine therapy by Pinchera et al. (1965), but later the level usually falls as demonstrated in Fig. 9 which shows serial LATS levels in one of our patients following a therapeutic dose of radio-iodine. The initial rise following the first dose does not occur $\frac{2}{3}$ following the second-the level falls accompanied $\underset{\complement}{\mathbb{Q}}$ by clinical improvement and achievement of $\stackrel{c}{.}$



FIG. 8. Plasma long-acting thyroid stimulator (LATS) level in relation to recurrence of hyperthyroidism following treatment. (Reproduced from Hoffmann \& Hetzel, Aust. Ann. Med., 1966).
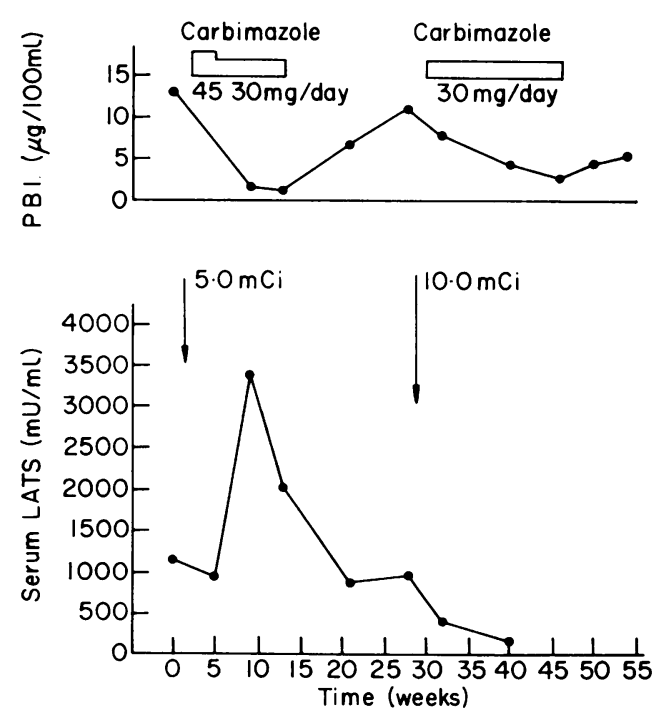

FIG. 9. Serial determinations of serum LATS before and after two radio-iodine therapy doses in a thyrotoxic patient, Mrs L.P. (aged 47), using the method of Mason et al. (1967). The patient has now remained euthyroid with very low LATS for a further 12 weeks. 
euthyroid status. These observations made with a recently developed improved bioassay for LATS (Mason et al., 1967) suggest the removal of an antigen by thyroid destruction.

These findings do suggest a rationale for the value of thyroid ablation in the treatment of thyrotoxicosis. However, the persistence of LATS in spite of apparently complete destruction of the thyroid has been reported by Kriss et al. (1964). Bauer \& Catz (1966) believe that small remnants of thyroid tissue can remain and if destroyed completely will lead to control of progressive exophthalmos if it has developed. This was not confirmed by Werner, Feind \& Aida (1967).

Corticosteroid therapy has been shown to be followed by a decrease in the serum LATS level and in some cases improvement in exophthalmos Snyder et al., 1964 ; Pimstone et al., 1963 ; Kriss et al., 1964). In a recent study a fall in serum LATS has been demonstrated following the administration of azathioprine (Fig. 10), although

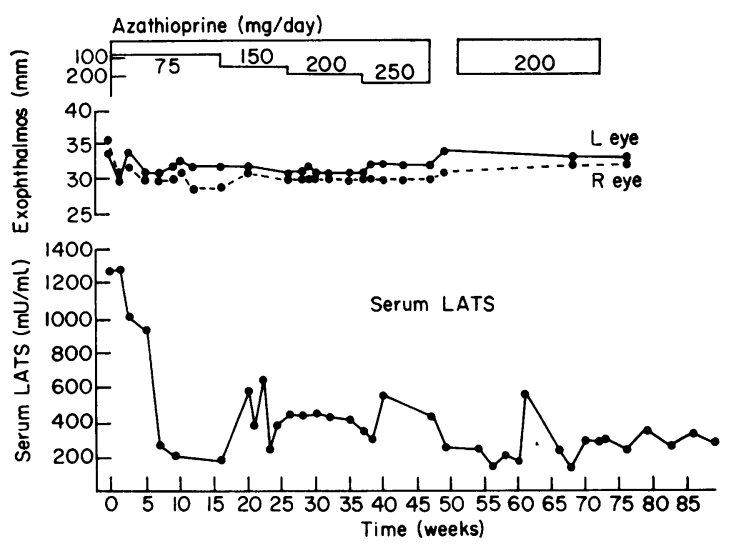

FIg. 10. Serial determinations of serum LATS before and during azathioprine therapy in a patient Mrs H.S. (aged 41) who had developed progressive exophthalmos, pretibial myxoedema and hypothyroidism following subtotal thyroidectomy for thyrotoxicosis 12 years before. (Method of Mason et al., 1967.)

no striking improvement occurred in the longstanding exophthalmos or pretibial myxoedema in this particular patient. It is of interest that withdrawal of steroid leads to worsening of ophthalmopathy and the reappearance of LATS in the serum (Snyder et al., 1964 ; Kriss et al., 1964). Local corticosteroid therapy to one leg has been followed by improvement in pretibial myxoedema on both sides with suppression of serum LATS (Kriss et al., 1964). Corticosteroid therapy has been followed by a fall in radio-iodine up- take when given to hyperthyroid patients who also had exophthalmos (Werner \& Platman, 1965) Similar effects on uptake and occasionally secretion rate as well have been observed following salicylate administration in hyperthyroidism (Good et al., 1966 ; Hetzel et al., 1960).

\section{Origin of LATS}

These clinical and laboratory data raise many fascinating questions concerning the aetiology and pathogenesis of hyperthyroidism. The longrecognized hyperplasia of lymphoid tissue and Warthin's original concept of a predisposing diathesis take on new significance.

Attention is directed to lymphoid tissue as the source of LATS as it is an immunoglobulin. However, it has not been possible to extract LATS from various lymphoid and other tissues at autopsy on suitable hyperthyroid patients (McKenzie, 1967). However, recent techniques of tissue culture have made it possible to study lymphocyte function in vitro. Lymphocytes may be separated from other blood constituents and cultured in a test-tube for a few days. Their function can be tested by measurement of the incorporation of a labelled amino acid such as ${ }^{14} \mathrm{C}$-leucine into proteins (Bach \& Hirschhorn, 1963 ; Forbes \& Turner, 1965). These lymphocyte preparations will respond to phytohaemagglutinin stimulation (Bach \& Hirschhorn, 1963; Forbes \& Henderson, 1966) and there is increasing evidence that they will produce antibody (IgG) under these conditions of nonspecific stimulation (Turner \& Forbes, 1966).

Culture of lymphocytes from subjects with past or present hyperthyroidism with high levels of serum LATS has been carried out with and without phytohaemagglutinin stimulation (McKenzie \& Gordon, 1965). The medium is collected every 1-3 days and assayed for LATS activity in the mouse. McKenzie \& Gordon (1965), by concentrating the medium on Sephadex G-25, were able to demonstrate significant activity which was not present without phytohaemagglutinin stimulation. Such a response could not be elicited from lymphocytes taken from a normal subject. It was possible to label the 7S globulin by incubation with ${ }^{14} \mathrm{C}$-labelled amino acids and demonstrate specific adsorption of the labelled $\gamma$-globulin on human thyroid microsomes but not human liver microsomes (McKenzie, 1967).

These studies certainly suggest that LATS is produced by lymphoid tissues but do not establish that it is an antibody. Such a conclusion awaits the demonstration of lymphocyte stimulation by a specific antigen. The demonstration 
of the source of LATS from lymphoid tissue, quite outside of normal feedback control, does however provide a mechanism that accounts for the non-suppressibility of the hypersecreting thyroid gland of hyperthyroidism (Adams, 1965).

\section{Thyrotoxicosis as an autoimmune disease}

All these findings raise the question of autoimmune mechanisms and whether thyrotoxicosis can be regarded as an autoimmune disease. This possibility can be considered in the light of the five criteria suggested by Milgrom \& Witebsky (1962). These criteria can be summarized as follows :

1. The direct demonstration of free circulating antibodies that are active at body temperature. This requirement would appear to be met by the data presented on the relation between LATS and clinical hyperthyroidism in the preceding section.

2. The recognition of a specific antigen in the human tissue involved in the disease. This is suggested though not established by the data of Beall \& Solomon (1966a, b) demonstrating the inactivation and binding of LATS by thyroid subcellular fractions-especially the microsomal fraction. In more recent studies, McKenzie (1967) has suggested that the microsomal fraction is a concentration of the endoplasmic reticulum which occurs throughout the cell, and this may be the site of action of LATS. Electron microscopic studies fail to reveal any difference between LATS and TSH in morphological effects on thyroid cells and there was no evidence that cell destruction was being produced as might be expected with an antigen-antibody reaction (McKenzie, 1967). The possibility that there are other tissues which may provide an antigen is raised by the clinical association with exophthalmos, myopathy and pretibial myxoedema.

3. The production of antibodies against the same antigen in experimental animals. Beall \& Solomon $(1966 \mathrm{a}, \mathrm{b})$ were unable to produce LATS activity in the serum of rabbits following injections of human thyroid microsomal material. However, more recently McKenzie (1967) has demonstrated rises in serum thyroxine in rabbits following administration of whole human thyroid extracts but not following a thyroid microsome or a liver microsome preparation. Gammaglobulin concentrates of rabbit serum revealed LATS-type activity (mouse assay) in the rabbits which had received the whole thyroid extracts but not in those receiving thyroid or liver microsomes. Much further work is required to establish whether thyrotoxicosis has really been pro- duced in an experimental animal but the data from these preliminary studies is suggestive.

4. The appearance of pathological changes in the corresponding tissues of an actively sensitized experimental animal that are basically similar to those of the human disease. This criterion has not been met as yet but it may be possible for it to be met in the light of McKenzie's most recent observations just cited which demonstrate suggestive functional if not as yet structural changes.

5. The successful transfer of the disease by an antibody-containing serum or by immunologically stimulated lymphoid cells. This criterion has clearly been met in the light of the data on neonatal thyrotoxicosis cited above where transient thyrotoxicosis has been associated with the presence of LATS in the circulation of the infantby passive transfer from the maternal circulation.

Mackay \& Burnet (1963) have defined autoimmune disease as a condition in which structural or functional damage is produced by the action of immunologically competent cells or antibodies against normal components of the body. They suggest that autoimmune disease is characterized by what are called 'markers' which include an elevated $\gamma$-globulin level (above $1.5 \mathrm{~g} / 100 \mathrm{ml}$ ), the presence of demonstrable 'autoantibody' against a body component, deposition of $\gamma$-globulin at certain sites, accumulation of lymphocytes and plasma cells in damaged tissues, and significant benefit from corticosteroid drugs or other immunosuppressive agents. There may also be evidence of other associated disease processes (possibly autoimmune) in the patient or her family.

In the case of thyrotoxicosis elevated $\gamma$-globulin is not usually present (Lamberg \& Grasbeck, 1955), neither so far has deposition of $\gamma$-globulin been demonstrated in thyroid cells though there is good evidence of lymphocytic infiltration. There is some evidence of benefit of steroid therapy in hyperthyroidism (Werner \& Platman, 1965) as well as in exophthalmos (Snyder et al., 1964). There is also evidence of benefit from salicylate (Good et al., 1966). Fall in serum LATS following azathioprine has already been shown (Fig. 10).

The association of thyrotoxicosis with other diseases has received increasing attention. There is a clinical association between thyrotoxicosis and pernicious anaemia (McNicol, 1961 ; Doniach Roitt \& Taylor, 1963). Doniach et al. (1963) have demonstrated a 6-7\% incidence of antibody to intrinsic factor in patients suffering from 
Graves' disease while parietal cell antibody micosomal fraction is present in no less than $33 \%$ of cases. The presence of this antibody is associated with thyroid antibodies (Anderson et al., 1964). There is also a clinical association between thyrotoxicosis and Addison's disease in that Blizzard \& Kyle (1963) found three cases of thyrotoxicosis in a series of sixty-eight patients with non-tuberculous Addison's disease. Irvine (1964) found two thyrotoxic patients in a series of fifteen cases of Addison's disease thought to be non-tuberculous. In one personal case thyrotoxicosis and exophthalmos preceded clinical Addison's disease by 15 years.

The association of Hashimoto's disease and thyrotoxicosis in individual patients and patients' families is well known (Anderson et al., 1964). Recently a significantly higher incidence of antithyroid antibodies (both to thyroglobulin and to microsomal antigen) has been shown in the mothers and sisters of thyrotoxic patients but not in fathers and brothers (Evans et al., 1967).

In a remarkable report Jayson et al. (1967) have described thyrotoxicosis and Hashimoto goitre in a pair of monozygotic twins born in 1928. The thyrotoxic twin also had progressive exophthalmos and asthma while the other had asthma and rheumatoid arthritis as well as Hashimoto's disease. The long-acting thyroid stimulator was demonstrable in the sera of both sisters although in the Hashimoto twin concentration of the IgG was necessary to obtain an unequivocal result. This is the first recorded instance of the presence of LATS in the serum of a patient who has not had thyrotoxicosis. These findings certainly suggest a common immunological defect and the significance of genetic factors.

In the light of all these data it would seem likely that thyrotoxicosis together with other diseases such as Hashimoto's disease and rheumatoid arthritis may arise as a genetically determined disturbance of immunological tolerance (Mackay \& Burnet, 1963 ; Irvine, 1964). In this connection it is of interest that medullary lymphoid follicles have been shown in the thymus in cases of thyrotoxicosis but not in cases of non-toxic goitre. These changes could be correlated with histological changes in the thyroid (Gunn, Michie \& Irvine, 1964).

In further consideration of thyrotoxicosis as an autoimmune disease the model presented by rheumatoid arthritis may be helpful (Kellgren \& Ball, 1959). Rheumatoid arthritis is a chronic disease subject to remission and relapse-often precipitated by non-specific factors in the form of infection or emotional disturbance with their associated steroid response (Hetzel, 1960). It is characterized by the presence in the serum of 'rheumatoid factor'-a 19S globulin detectable by agglutination of sensitized sheep red cells (SCAT). This agent was detectable in $98 \%$ of 152 classical rheumatoid cases with subcutaneous nodules while it is detectable in only $70 \%$ of sixty-four patients less than 12 months after onset of the disease and in $68 \%$ of forty-one atypical cases. It was present in only $6-7 \%$ of 1392 patients with other forms of arthritis and $5.7 \%$ of 1165 random patients, the proportion of positive cases increasing with age. Positive tests were also found in $20 \%$ of blood relatives of probands with positive tests suggesting that the presence of SCAT is genetically determined (Kellgren \& Ball, 1959). Both diseases characteristically affect females more than males. Can this be related to the $\mathrm{XX}$ chromosome?

It has already been shown that the incidence of LATS differs in sera taken from patients with varying clinical features of hyperthyroidism. So far the difficult method of bioassay is the only one available for detection of LATS. As concentration procedures for $\gamma$-globulin become more readily available and when an in vitro immunoassay finally is developed we may well find that LATS joins the other immunoglobulins like the rheumatoid factor in exhibiting the iceberg phenomenon and varying genetic penetrance. Activation of thyrotoxicosis can occur though various environmental factors including nonspecific stress due to emotional disturbance or infection accompanied by an adrenal steroid response, iodine deficiency or other unknown factors. This view suggests that control is achieved through thyroid ablation by removal of the antigen or by blocking biosynthesis with an antithyroid drug until natural remission occurs.

\section{Acknowledgments}

The author has enjoyed the active collaboration and assistance of Dr M. L. Wellby, Dr B. F. Good, Dr M. J. Hoffmann, Dr I. H. Buttfield, Dr J. S. Charnock, Mrs Margaret Black and Miss Edith Mason over the past 10 years. Dr I. J. Forbes has given much helpful advice and Mrs J. Todd expert secretarial assistance. This work has been supported by the Michell Foundation of the University of Adelaide and the National Health and Medical Research Council of Australia.

\section{References}

ADAMS, D.D. (1958) The presence of an abnormal thyroid stimulating hormone in the serum of some thyrotoxic patients. J. clin. Endocr. 18, 669.

ADAMS, D.D. (1961) Bioassay of long acting thyroid stimulator (L.A.T.S.). The dose response relationship. J. clin. Endocr. 21, 799.

ADAMS, D.D. (1965) Pathogenesis of the hyperthyroidism of Graves' Disease. Brit. med. J. i, 1015. 
ADAmS, D.D. \& KenNedy, T.H. (1965) Evidence of a normally functioning pituitary TSH secretion mechanism in a patient with a high blood level of long-acting thyroid stimulator. J. clin. Endocr. 25, 571.

Adams, D.D., Kennedy, T.H., PuRves, H.D. \& SiretT, N. (1962) Failure of TSH antisera to neutralise long acting thyroid stimulator. Endocrinology, 70, 801.

ADAms, D.D. \& Sharard, A. (1965) Neutralization of long acting thyroid stimulator by antibodies to euthyroid human serum. Aust. Ann. Med. 14, 192.

Anderson, J.R., Gray, K.G., Middleton, D.G. \& Young, J.A. (1964) Autoimmunity and thyrotoxicosis. Brit. med.J. ii, 1630.

BACH, F. \& HiRsCHHORN, K. (1963) Gammaglobulin production by human lymphocytes in vitro. Exp. Cell Res. 32, 592.

BARTELS, E.D. (1941) Heredity of Graves Disease. Munksgaard, Copenhagen

BAUER, F.K. \& CATZ, B. (1966) Radioactive iodine therapy for progressive malignant exophthalmos. Acta endocr. $(K b h), 51,15$.

Beall, G.N. \& Solomon, D.H. (1966a) Inhibition of long acting thyroid stimulator by thyroid particulate fractions. J. clin. Invest. 45, 552.

Beall, G.N. \& Solomon, D.H. (1966b) On the immunological nature of the long acting thyroid stimulator. J. clin. Endocr. 26, 1382.

BIRD, R. \& FARRAN, H.E.A. (1960) A sensitive method for the detection of iodinated compounds in human plasma and its application to the study of thyrotoxicosis. J. clin. Endocr. 20, 81.

Blizzard, R.M. \& KYle, M. (1963) Studies of the adrenal antigens and antibodies in Addison's Disease. $J$. clin. Invest. 42, 1653.

BOARD, F. WADESON, R. \& PERSKY, H. (1957) Depressive affect and endocrine functions. Arch. Neurol. Psychiat. 78, 612.

Brown, L.B. \& Hetzel, B.S. (1963) Stress, personality and thyroid disease. J. psychosom. Res. 7, 223.

Brown Grant, K., Harris, G.W. \& Reichlin, S. (1954) The effect of emotional and physical stress on thyroid activation in the rabbit. J. Physiol. (Lond.), 126, 29.

Carneiro, L., Dorrington, K.J. \& Munro., D.S. (1966a) Relation between long acting thyroid stimulator and thyroid function in thyrotoxicosis. Lancet, ii, 878.

Carneiro, L., Dorrington, K.J. \& Munro, D.S. (1966b) Recovery of long acting thyroid stimulator from serum of patients with thyrotoxicosis by concentration of imunoglobulin G. Clin. Sci. 31, 215.

Clements, F.W. (1954) The relationship of thyrotoxicosis and carcinoma of the thyroid to endemic goitre. Med. J. Aust. ii, 894.

Clements, F.W. (1960) Endemic Goitre. W.H.O. Monograph, Geneva.

CoHen, S. \& Porter, R.B. (1964) Structure and biological activity of immunoglobulins. Advanc. Immunol. 4, 287.

ConRad, A. (1934) The psychiatric study of hyperthyroid patients. J. nerv. ment. Dis. 79, 505 .

Dobyns, B.M., RudD, A. \& LiEbe, D. (1965) The assay of exophthalmos producing substance (EPS) and the long acting thyroid stimulator (LATS) in whole and fractionated serum of patients with progressive exophthalmos. Current Topics in Thyroid Research. Proceedings 5th International Thyroid Conference (Ed. by C. Cassano and $\mathrm{M}$. Andreoli), p. 484. Academic Press, New York.

DoniaCh, D., RoITt, I. \& TAYLOR, K.B. (1963) Auto-immune phenomena in pernicious anaemia. Brit. med. J. i, 1374.

Dorrington, K.J., Carneiro, L. \& Munro, D.S. (1965) Chemical Studies on the long acting thyroid stimulator. Current Topics in Thyroid Research. Proceedings 5th Inter, national Thyroid Conference (Ed. by C. Cassano and $\mathbf{M}$. Andreoli), p. 455. Academic Press, New York.
DoRrington, K.J. \& MUNRo, D.S. (1965) Immunological studies on the long acting thyroid stimulator. Clin. Sci. 28, 165.

Evans, A.W.H., Woodrow, J.C., McDougall, C.D.M., Chew, A.R. \& Evans, R.W. (1967) Antibodies in the families of thyrotoxic patients. Lancet, i, 636.

FAlCONER, I.R. \& HeTZEL, B.S. (1964) Effect of emotional stress and TSH on thyroid vein hormone level in sheep with exteriorized thyroids. Endocrinology, 75, 42.

FarRaN, H.E.A., Lea, H.J., Goolden, A.W.G. \& AbBotT, J.D. (1959) Iodinated tyrosines in the plasma of patients with thyrotoxicosis. Lancet, i, 793.

Flodin, P. \& KIllandeR, J. (1962) Fractionation of human serum fractions by gel filtration. Biochim. biophys. Acta (Amst.), 63, 403.

FORBES, I.J. \& HENDERSON, D.W. (1966) Globulin synthesis by human peripheral lymphoctyes. Ann. intern. Med. 65, 69.

FORBES, I.J. \& TURNER, K.J. (1965) Synthesis of protein by human lymphocytes in vitro. I. Clinical studies. Aust. Ann. Med. 14, 304.

Good, B.F., Hetzel, B.S., Hoffman, M.J., Wellby, M.L. BlACK, M.L., PotTer, H.A. \& ButTfield, I.H. (1966) Studies of the effects of salicylate in hyperthyroidism. Aust. Ann. Med. 15, 143.

GreENWALD, I. (1962) Increases in deaths due to exophthalmic goitre, 1925-1951. Acta endocr. (Kbh.), Suppl. 67.

GreENWALD, I. (1965) The significance of the increased mortality from exophthalmic goitre in Australia after 1923. Med. J. Aust. i, 836.

Grelland, R. (1946) Thyrotoxicosis at Ulleval Hospital in the years 1934-1944 with a special view to frequency of the disease. Acta med. scand. 125, 108.

Gross, J. \& Pitt-Rivers, R. (1952) The identification of 3-5-3' triiodothyronine in human plasma. Lancet, i, 439

GunN, A., Michie, W. \& IRvine, W.J. (1964) The thymus in thyroid disease. Lancet, ii, 776.

HARRIS, G.W. \& Woods, J.D. (1958) The effect of electrical stimulation of the hypothalamus or pituitary gland on thyroid activity. J. Physiol. (Lond.), 143, 246.

Harvald, B. \& Hauge, M. (1956) A catamnestic investigation of Danish twins. Dan. med. Bull. 3, 150.

Hassan, T.H.A., Greig, W.R., Boyle, J.A., Boyle, I.T. \& Wallace, T.J. (1966) Toxic diffuse goitre in monozygotic twins. Lancet, ii, 306.

Hetzel, B.S. (1960) Cannon revisited: Emotions and bodily changes-their relevance to disease. Med. J. Aust. i, 193.

Hetzel, B.S., Charnock, J.S., Gilmore, H. \& LeMercier, K. (1958) Alteration of metabolic response to adrenaline in man by pretreatment with triiodothyronine and hydrocortisone. Aust. J. exp. Biol. med. Sci. 36, 479.

Hetzel, B.S., Good, B.F., Wellby, M.L. \& Charnock, J.S. (1960) Salicylate induced fall in plasma PBI in hyperthyroidism. Lancet, i, 957.

Hetzel, B.S., Mason, E.K. \& Wang, K.H. (1968) Clinical experience with serum LATS in relation to exophthalmos after therapy for thyrotoxicosis. Aust. Ann. Med. (In press).

Hetzel, B.S., Schottstaedt, W.W., Grace, W.J. \& WolfF, H.G. (1956) Changes in urinary nitrogen and electrolyte excretion during stressful life experiences and their relation to thyroid function. J. psychosom. Res. 1, 177 .

HoffmanN, M.J. \& Hetzel, B.S. (1966) The clinical significance of plasma thyroid stimulating activity in hyperthyroidism. Aust. Ann. Med. 15, 204.

HoffmanN, M.J., Hetzel, B.S. \& Manson, J. (1966) Neonatal thyrotoxicosis: Report of three cases involving four infants. Aust. Ann. Med. 15, 262.

Hoffmann, M.J., Mason, E.K., Good, B.F., Hetzel, B.S. \& FERGUSON, K. (1967) Studies of the nature of plasma thyroid stimulating activity in hyperthyroidism. Aust. Ann. Med. 16, 98 . 
Ingbar, S.H., Freinkel, N., Dowling, J.T. \& Kumagai, L.F. (1956) Abnormalities of iodine metabolism in euthyroid relatives of patients with Graves' disease. J. clin. Invest. 35, 714.

IRviNe, W.J. (1964) Thyroid autoimmunity as a disorder of immunological tolerance. Quart. J. exp. Physiol. 49, 324.

Jayson, M.I.V., DoniaCh, D., Benhamou-GlynN, N., RoITT, I.M. \& ElkabIR, D.J. (1967) Thyrotoxicosis and Hashimoto's goitre in a pair of monozygotic twins with serum long acting thyroid stimulator. Lancet, ii, 15.

Kellgren, J.H. \& Ball, J. (1959) Clinical significance of the rheumatoid serum factor. Brit. med. J. i, 523.

KEYNES, G. (1952) Obstetrics and gynaecology in relation to thyrotoxicosis and myasthenia gravis. J. Obstet. Gynaec. Brit. Emp. 59, 173.

Kriss, J.P., Pleshakov, V. \& Chien, J.R. (1964) Isolation and identification of the long acting thyroid stimulator and its relation to hyperthyroidism and circumscribed pretibial myxoedema. J. clin. Endocr. 24, 1005.

Kriss, J.P., Pleshakov, V., Rosenblum, A. \& Chien, J.R. (1965) Studies on the formation of long acting thyroid stimulator globulin (L.A.T.S.) and the alteration of its activity by enzymatic digestion and partial chemical degradation. Current Topics in Thyroid Research. Proceedings 5th International Thyroid Conference (Ed. by C. Cassano and M. Andreoli), p. 433. Academic Press, New York.

LAMBERG, B.A. \& GRASBECK, R. (1955) The serum protein pattern in disorders of thyroid function. Acta. endocr. (Kbh.), 19, 91.

Liddle, G.W., Heyssel, R.M. \& McKenzie, J.M. (1965) Graves Disease without hyperthyroidism. Amer. J. Med. 39, 845.

MCClENDoN, J. (1939) Iodine and the Incidence of Goiter. University of Minnesota Press, Minneapolis.

MCClure, R.D. (1934) Thyroid surgery as affected by the generalized use of iodized salt in an endemic goitre regionpreventive surgery. Ann. Surg. 100, 924.

MCGiven, A.R., Adams, D.D. \& Purves, H.D. (1965) A comparison of the heat stability of long-acting thyroid stimulator and human thyroid-stimulating hormone. J. Endocr. 32, 29.

MCKenzIE, J.M. (1958) Delayed thyroid response to serum from thyrotoxic patients. Endocrinology, 62, 865.

McKenzie, J.M. (1961) Studies on the thyroid activator of hyperthyroidism. J. clin. Endocr. 21, 635.

MCKENZIE, J.M. (1962) Fractionation of plasma containing the long acting thyroid stimulator. J. biol. Chem. 237, 3571 .

McKenzIE, J.M. (1964) Neonatal Graves Disease. J. clin. Endocr. 24, 660.

McKenziE, J.M. (1967) The long acting thyroid stimulator. Recent Progr. Horm. Res. 1, 1.

McKenzie, J.M. \& Fishman, J. (1960) Effect of antiserum on bioassay of thyrotropin and thyroid activator of hyperthyroidism. Proc. Soc. exp. Biol. (N.Y.), 105, 126.

MCKenzie, J.M. \& Gordon, J. (1965) The origin of the long acting thyroid stimulator. Current Topics in Thyroid Research' Proceedings 5th International Thyroid Conference (Ed. by C. Cassano and M. Andreoli), p. 445, Academic Press, New York.

MACKAY, I.R. \& BURNET, F.M. (1963) Autoimmune Diseases. Thomas, Springfield, Illinois.

Maclagan, H.F., Bowden, C.H. \& Wilkinson, J.H. (1957) The metabolism of thyroid hormones. 2. Detection and determination of thyroxine and triiodothyronine in human plasma. Biochem. J. 67, 5.

MCNicol, G.P. (1961) Thyrotoxicosis associated with pernicious anaemia. Amer. J. med. Sci. 241, 336.

MARINE, D. (1935) The physiology and principal interrelations of the thyroid. J. Amer. med. Ass. 104, 2250.

MARINE, D. (1954) Endemic goitre: A problem in preventive medicine. Ann. intern. Med. 41, 875.
MARINe, D. \& Rosen, S.H. (1934) The exophthalmos of Graves' Disease-its experimental production and significance. Amer. J. med. Sci. 188, 565.

MARTIN, L. \& FisheR, R.A. (1945) The hereditary and familial aspect of exophthalmic goitre and nodular goitre. Quart. J. Med. 14, 207.

Mason, E.K. Hetzel, B.S., Good, B.F. \& Stenhouse, N.S. (1967) An improved bioassay for long acting thyroid stimulator (LATS). J. clin. Endocr. 27, 1529.

Means, J.H. (1937) The Thyroid and its Diseases. Lippincott, Philadelphia.

Means, J.H., De Groot, L.J. \& Stanbury, J.B. (1963) The Thyroid and its Diseases, 3rd edn. Blakiston Division, McGraw-Hill, New York.

MEUlengraChT, E. (1945) Increasing incidence of hyperthyroidism in Denmark. Acta med. scand. 121, 446.

MeUlengraCHT, E. (1949) Epidemiologic aspects of thyrotoxicosis. Arch. intern. Med. 83, 119.

Milgrom, F. \& Witebsky, E. (1962) Autoantibodies and autoimmune diseases. J. Amer. med. Ass. 181, 706.

MIYAI, K. \& WERNER, S.C. (1966) Concentration of long acting thyroid stimulator (LATS) by subfractionation of gamma $\mathbf{G}$ globulin from Graves' Disease serum. J. clin. Endocr. 26, 504.

MUNRO, D.S. (1959) Observations on the discharge of radioiodine from the thyroid glands of mice injected with human sera. J. Endocr. 19, 64.

Munro, D.S., Major, P.W. \& Wilson, G.M. (1960) Proceedings of the Association of Physicians of Great Britain and Ireland. Quart. J. Med. 29, 631.

Niall, H.D., Wellby, M.L., Hetzel, B.S., Hudson, B. \& Chenoweth, R.A. (1968) Biochemical and clinical studies in familial goitre due to an iodotyrosine deiodinase defect. Aust. Ann. Med. (In press).

Noguchi, A., Kurihara, H. \& Sato, S. (1964) Clinical studies on long acting thyroid stimulator. J. clin. Endocr. 24, 160.

Odell, W.D., Wilber, J.F. \& Paul, W.E. (1965) Radioimmunoassay of thyrotropin in human serum. J. clin. Endocr. 25, 1179.

PARrY, C.H. (1825) Quoted by MaJor, R.A. (1948) Classic descriptions of disease. Collected Works, Vol. 1, p. 478.

PerINETTI, H. (1952) Medical surgical experience with goiter in endemic district. Trans. Amer. Ass. Goiter, p. 12.

Perez, C., Scrimshaw, S.W. \& Munez, J.A. (1948) Technique of endemic goiter surveys. Bull. Wld Hlth Org. 18, 217.

Pimstone, B.L., HoffenberG, R. \& Black, E. (1963) Parallel assays of thyrotrophin, long acting thyroid stimulator and exophthalmos producing substance in some endocrine disorders. J. clin. Endocr. 23, 336.

Pinchera, A., Pinchera, M.G. \& Stanbury, J.B. (1965) Thyrotropin and long acting thyroid stimulator assays in thyroid disease. J. clin. Endocr. 25, 189.

Plummer, H.S. (1931) Exophthalmic goitre in Olmsted County, Minnesota. Trans. Asso. Amer. Phycns, 46, 171.

Purves, H.D. \& Adams, D.D. (1960) Thyroid stimulating hormone. Brit. med. Bull. 16, 128.

Shizume, K., Matsuzaki, F., IION, S., Matsuda, K., NAGATAKI, S. \& OKINAKA, S. (1962) Effect of electrical stimulation of the limbic system on pituitary thyroidal function. Endocrinology, 71, 456.

Stanbury, J.B., KassenaAr, A.A.H., MeiJer, J.W.A. \& Terpstra, J. (1955) The occurrence of mono- and diiodotyrosine in the blood of a patient with congenital goitre. J. clin. Endocr. 15, 1216.

SNYDER, N.J., Green, D.E. \& Solomon, D.H. (1964) Glucocorticoid induced disappearance of long acting thyroid stimulator in the ophthalmopathy of Graves' Disease. J. clin. Endocr. 24, 1129.

TINGleY, T.O., MoRriss, W.O. \& Hill, S.R. (1958) Studies on the diurnal variation and response to emotional stress of the thyroid gland. Clin. Res. 6, 134. 
TURNER, K.J. \& FORBES, I.J. (1966) Synthesis of proteins by human leukocytes in vitro. J. Immunol. 96, 826.

WARTHIN, A.S. (1928) The constitutional entity of exophthalmic goiter and so-called toxic adenoma. Ann. intern. Med. 2, 553.

Wellby, M.L. \& Hetzel, B.S. (1962) Demonstration of iodotyrosines in human plasma in response to thyroid stimulation. Nature (Lond.), 193, 152.

Wellby, M.L., Hetzel, B.S. \& Good, B.F. (1963a) The circulating thyroid hormones in thyrotoxicosis. Brit. med. J. i, 439.

Wellby, M.L., Hetzel, B.S. \& IsaAchsen, M.L. (1963b) The effect of thyrotropic hormone on the plasma thyroid hormones in man. Aust. Ann. Med. 12, 30.
WERnER, S.C. (1955) The Thyroid. Hoeber-Harper, New York.

Werner, S.C. FeIND, C.R. \& AIDA, M. (1967) Graves' Disease and total thyroidectomy. New Engl. J. Med. 276, 132.

Werner, S.C., Otero-Riviz, E., Segal, B.C. \& Bates, R.W. (1960) Neutralization of human serum and pituitary thyrotropic fractions with antisera to bovine pituitary thyrotropin. Nature (Lond.), 185, 472.

Werner, S.C. \& Platman, S.R. (1965) Remission of hyperthyroidism (Graves' Disease) and altered pattern of serum thyroxine binding induced by prednisone. Lancet, ii, 751 . 